Original Research Paper

\title{
Effects of Oak Chip Treatments on Quality of Dry White Wines During Aging
}

\author{
Rongbin Li, Xiaofang Liang, Chunhua Song, Haoran Wang, \\ Yaqiong Liu, Yanli Ma, Jianfeng Sun and Jie Wang \\ College of Food Science and Technology, Hebei Agricultural University, Hebei, 071000, China
}

\author{
Article history \\ Received: 12-11-2019 \\ Revised: 13-01-2020 \\ Accepted: 25-02-2020 \\ Corresponding Author: \\ Jie Wang \\ College of Food Science and \\ Technology, Hebei \\ Agricultural University, Hebei, \\ 071000, China \\ Email:wj591010@163.com
}

\begin{abstract}
The objective of the research was to evaluate the effect of different oak chip treatments on quality of Longyan dry white wine during aging. Phenolic substances, antioxidant activity and $\mathrm{Cu}^{2+}$ reduction force were measured. The results showed that wines treated with French oak chips $(6 \mathrm{~g} / \mathrm{L})$ had significantly higher contents of total phenols $(0.083$ $\mathrm{mg} / \mathrm{mL})$ and flavonoids $(0.063 \mathrm{mg} / \mathrm{mL})$, also the highest total antioxidant capacity $(47.853 \mathrm{U} / \mathrm{mL})$ was observed. However the scavenging rate of DPPH free radicals and hydroxyl radical scavenging rate were the highest in samples aged with American oak chips (6 g/L) and Yanshan oak chips (2 g/L), respectively. As for 12 monomer phenols determined by high-performance liquid chromatography, French oak chips can contribute to the formation of monomer phenols, especially the generation of syringaldehyde $(15.134 \mathrm{mg} / \mathrm{L})$ and guaiacol $(17.345 \mathrm{mg} / \mathrm{L}) . \mathrm{Cu}^{2+}$ reduction ability of wine sample increased with the increase of oak chips content. Correlation analysis revealed that the monomer phenols had a strong correlation with total antioxidant capacity, DPPH radical scavenging rate and hydroxyl radical scavenging rate. Understanding the influence of oak chips on wine properties could aid to lay a theoretical foundation for the effective use of oak chips in wine.
\end{abstract}

Keywords: Longyan Dry White Wine, Aging, Phenols, Antioxidation

\section{Introduction}

Longyan dry-white wine is fermented with pure Longyan grape juice. With its yellowish and green color, clarity and translucence and fresh fruity aroma, it is recognized as "Oriental Wine" by European and American wine experts. After fermentation, this wine adopts a sour and poor taste and is unsuitable for drinking, therefore, its aging takes a long time. The aging process is one of the fundamental steps to obtained high-quality wine and it promotes wine maturity and improves sensory properties (Bautista-Ortín et al., 2008; Cerdán and Ancín-Azpilicueta, 2006; Alamo-Sanza et al., 2019). Through aging, the wine obtains a stable color, complex aroma and improved taste because it loses its astringency and bitterness (Crump et al., 2015). The aging of wine is usually conducted in oak barrels. However, aging wine in barrels requires long periods of contact time. Traditional maturation systems are costly and laborious due to the high price of barrels, limited lifetime, large space and maintenance requirement. Therefore, oak products, such as oak planks, blocks and slices, have been used in recent years instead of oak barrels to save money and short the aging time (Coelho et al., 2019; Guchu et al., 2005).
Currently, the two most important varieties of oak chose for wine aging are the French Quercus Robur and the American Quercus fabri (Bozalongo et al., 2007; Cerdán et al., 2002; Gordillo et al., 2016). French and American oaks have important differences in terms of chemical composition. French oak has more phenolic compounds, ellagiotannins and extractable soluble substances and the lignin modified phenolic resin extracted from oak have the metal adsorption capacity of $\mathrm{Cd}^{2+}$ with sustainability, low production cost and environmental control (Arasaretnam and Kirudchayini, 2019). Differences have also been found between them in terms of $\mathrm{C} 13$ compounds and norisoprenoids composition (Cerdán et al., 2002). China's domestic oak is known as eucalyptus, which is mainly distributed in the secondary forest species in the northeastern forest area of China. The Chinese eucalyptus, French oak and the American oak belong to the same family. The Chinese eucalyptus is cold-tolerant, drought-tolerant and growth-resistant. In terms of shape, fruit, texture and scent, Chinese eucalyptus is similar with imported oak and has considerable potential for wine aging. 


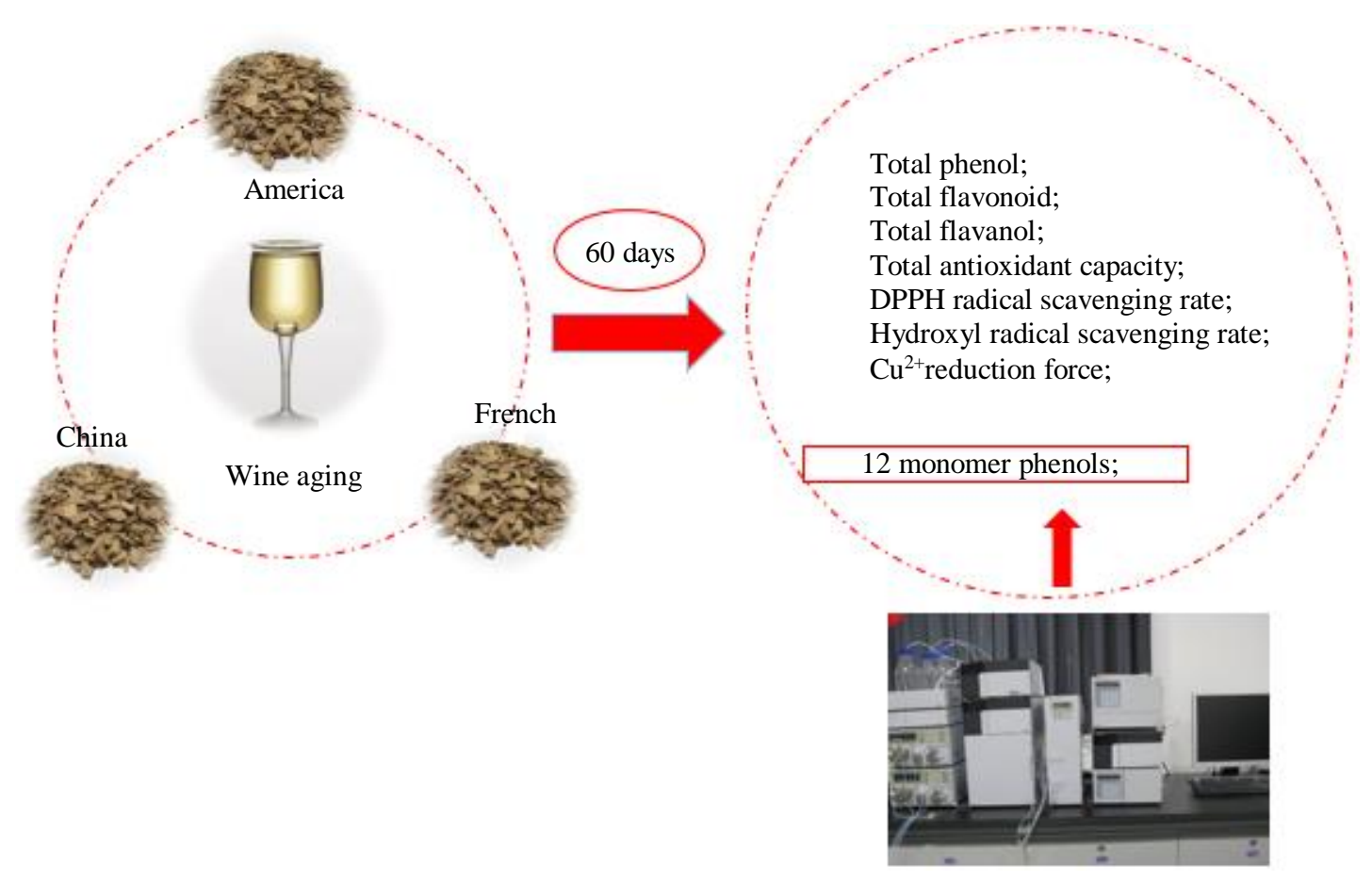

Fig. 1: Research methods in this study

Phenolic compounds are important substances in wine because they not only directly or indirectly affect the color, taste and aroma of wines but are also closely related to their antioxidant activity. DPPH method is widely used for quantitative determination of antioxidant capacity and DPPH can be used as a substance to monitor reactions in chemical reactions containing free radicals (Mahboubi and Mahboubi 2015). Meanwhile, hydrogen peroxide scavenging activity can be used to evaluate antioxidant capacity and some authors reported that phenols have the ability to scavenge hydrogen peroxide (Prahadeesh et al., 2018). The relationship between phenols and antioxidant capacity can be demonstrated by a multivariate statistical analysis, the multivariate statistical analysis is generally used to evaluate the correlation between variables. For example, a multi-objective optimization model is developed to allocate the agricultural and environmental water (Sedghamiz et al., 2018). The phenolic substances in wine differ with the variety of grapes, brewing process and method of aging. With oak-aged wine, the lignin in oak degrades to form volatile phenols and phenolic compounds (Canas et al., 2019; Gómez GarcíaCarpintero et al., 2012). However, there is little known about wine produced from longyan white grape varieties and specifically about the aging of the wine.

The aim of this study was to determine the effects of (i) three types of oak slices (Yanshan, American and French) and (ii) different addition amount (2, 4 and 6 $\mathrm{g} / \mathrm{L}$ ) on the final quality of Longyan dry white wine over the course of a 60 day aging, total phenolics, total flavonoids, total flavanols, monomeric phenol, antioxidant activity and $\mathrm{Cu}^{2+}$ reduction force were measured and correlation analysis was used to evaluate the contribution of phenolic substances measured to the antioxidant capacity. The research method of this paper is showed in Fig. 1. Further it lay the foundation for the extensive use of oak chips in aged wine in wine industry.

\section{Materials and Methods}

\section{Chemicals and Reagents}

Gallic acid, protocatechuic acid, catechin, vanillic acid, syringic acid, coumalic acid, syringaldehyde, ferulic acid, guaiacol, benzoic acid, salicylic acid, quercetin, $\rho$-DMACA, neocuproin, a water-soluble analog of Vitamin E and DPPH were all purchased from Shanghai Yuanye Biotechnology Co., Ltd. Total antioxidant capacity kit was purchased from Nanjing Institute of Bioengineering. Other reagents were of analytical grade.

\section{Samples}

Samples of Longyan dry white wine from the 2017 vintage were industrially manufactured in a winery named Aristocratic Manor, Huailai County, Hebei Province and China. The base parameters of the 
Longyan dry white wine were as follows: Alcohol content $12 \%$ vol, $\mathrm{pH} 3.63$, total acidity $7.11 \mathrm{~g} / \mathrm{L}$ and reduced sugar $0.18 \mathrm{~g} / \mathrm{L}$.

American/French oak slices were purchased from Saiprisin (Beijing) Technology Co. Ltd., with dimensions of approximately $10 \times 5 \times 2 \mathrm{~mm}$, moderately baked $200 \pm 10^{\circ} \mathrm{C}$ and baked for $30 \mathrm{~min}$. Yanshan oak slices were purchased from the 20-year-old eucalyptus base of Guojiatun Town, Longhua County, Hebei Province, China, with specifications of approximately $10 \times 5 \times 2 \mathrm{~mm}$, moderately baked $200 \pm 10^{\circ} \mathrm{C}$ for $30 \mathrm{~min}$.

\section{Aging of Wine}

A total of three kinds of oak slices were used for aging. These oak slices were added to the base wine according to addition amounts of 2, 4 and $6 \mathrm{~g} / \mathrm{L}$ and aged for 60 days at room temperature. Afterward, the samples were analyzed. Each oak treatment was set in three parallels and compared with wines aged at the same temperature and storage time without oak slices.

\section{Determination of Total Phenolics, Total Flavonoids and Total Flavanols}

Total phenols were determined by folin-phenol colorimetry with 752 UV-visible spectrophotometer (Shanghai Jinghua Technology Instrument Co., Ltd.) (Baiano et al., 2015). A total of $0.1 \mathrm{~mL}$ sample was added into a $10 \mathrm{~mL}$ volumetric bottle for taste and then $6 \mathrm{~mL}$ distilled water, $0.5 \mathrm{~mL}$ folin-phenol reagent and $1.5 \mathrm{~mL} \mathrm{Na}_{2} \mathrm{CO}_{3}$ were quickly added after fully mixing the solution. The capacity was finally fixed with distilled water. The solution was placed at $20^{\circ} \mathrm{C}$ for $2 \mathrm{~h}$ and then UV-visible spectrophotometer was used to determine the absorbance value of each solution at the wavelength of $765 \mathrm{~nm}$. The results were expressed in terms of gallic acid equivalent.

The determination of total flavonoids was performed according to the methodology (Sánchez-Palomo et al., 2017). A total of $0.5 \mathrm{~mL}$ sample was added for taste and $0.5 \mathrm{~mL}$ ethanol and $0.15 \mathrm{~mL} 0.5 \mathrm{~mol} / \mathrm{L} \mathrm{NaNO}_{2}$ were added to the $10 \mathrm{~mL}$ volumetric bottle and fully mixed. A total of $0.15 \mathrm{~mL} 0.3 \mathrm{~mol} / \mathrm{L} \mathrm{AlCl}_{3}$ was then added $5 \mathrm{~min}$ later, followed by the addition of $1 \mathrm{~mL} 1$ $\mathrm{mol} / \mathrm{L} \mathrm{NaOH}$ and $2 \mathrm{~mL}$ distilled water after $10 \mathrm{~min}$. The absorbance was determined at $510 \mathrm{~nm}$ and read against a blank solution. Concentrations were calculated in terms of catechin.

Total flavanols were determined by $\rho$-DMACA (Kyraleou et al., 2015). A total of $0.3 \mathrm{~mL}$ sample was added for taste and $0.7 \mathrm{~mL}$ distilled water, $1 \mathrm{~mL} 0.24$ $\mathrm{mol} / \mathrm{L} \mathrm{HCl}$ and $1 \mathrm{~mL} 0.2 \% \rho$-DMACA were added to the $10 \mathrm{~mL}$ volumetric bottle. After a $2 \mathrm{~h}$ incubation of the mixture at $20^{\circ} \mathrm{C}$, the absorbance was determined at 640 $\mathrm{nm}$ and read against a blank solution. Concentrations were calculated as catechin.

\section{Determination of Monomeric Phenol}

A total of $10 \mathrm{~mL}$ of the wine was took and extracted thrice with $10 \mathrm{~mL}$ ethyl acetate. Afterward, the organic phase was combined and concentrated by rotary evaporation to dryness. The mixture was reconstituted with $3 \mathrm{~mL}$ chromatographic methanol and stored at $-20^{\circ} \mathrm{C}$ in the dark for liquid chromatography.

The determination of monomeric phenol was carried out by Waters 1525 HPLC system equipped with UV detector and an Agilent column C-18 $(250 \times 4.6 \mathrm{~mm}, 5 \mu \mathrm{m})$ at $30^{\circ} \mathrm{C}$. The detection was performed at $280 \mathrm{~nm}$. The mobile phase consisted of a $2 \%$ glacial acetic acid (eluent A) and an acetonitrile (eluent B). The flow rate was 1 $\mathrm{mL} / \mathrm{min}$. The solvent gradient was as follows: $97-90 \% \mathrm{~A}$ (0-5 min), $90-85 \%$ A (5-15 min), 85-70\% A (15-35 min), $70-97 \%$ A (35-40 min).

\section{Determination of Antioxidant Activity}

The total antioxidant capacity was determined according to the kit instructions. The absorbance value of the reaction system was increased by 0.01 per $\mathrm{mg}$ of solution per minute at $37^{\circ} \mathrm{C}$ as a unit of total antioxidant capacity.

The determination of DPPH free radicalscavenging rate was determined. A total of $1 \mathrm{~mL} 0.2$ $\mathrm{mmol} / \mathrm{L}$ DPPH ethanol solution, $1 \mathrm{~mL}$ distilled water and $1 \mathrm{~mL}$ sample wine were added to the plug-in tube, fully mixed and then incubated at room temperature for $20 \mathrm{~min}$ in the dark. The Absorbance (As) was then measured at $517 \mathrm{~nm}$. The blank group used $1 \mathrm{~mL}$ absolute ethanol instead of DPPH ethanol solution and the Absorbance $(\mathrm{Ax})$ was measured; by contrast, the control group used $1 \mathrm{~mL}$ distilled water instead of the sample to measure the Absorbance (Ao). The blank was finally zeroed with an equal volume of distilled water and absolute ethanol mixture.

The hydroxyl radical-scavenging rate was determined according to the methodology (Apak et al., 2004). The reaction mixture comprised the addition of $100 \mu \mathrm{L} 0.02 \mathrm{~mol} / \mathrm{L} \mathrm{FeSO}_{4}, 45 \mu \mathrm{L} 0.15 \% \mathrm{H}_{2} \mathrm{O}_{2}$ and 1 $\mathrm{mL} 8 \mathrm{mmol} / \mathrm{L}$ salicylic acid into $4 \mathrm{~mL}$ distilled water. The solution was mixed thoroughly and then $120 \mu \mathrm{L}$ sample wine was added. The absorbance was read at $593 \mathrm{~nm}$ after $4 \mathrm{~min}$ incubation at an ambient temperature of $3^{\circ} \mathrm{C}$ in the dark against a blank of distilled water and control of absolute ethanol.

The determination of the $\mathrm{Cu}^{2+}$ reduction ability was performed according to the methodology of Apak et al. (2004). The reaction mixture contained $200 \mu \mathrm{L}$ sample wine, $2 \mathrm{~mL}$ distilled water, $0.3 \mathrm{~mL} 5 \mathrm{mmol} / \mathrm{L} \mathrm{CuSO}_{4}$ 
and $0.3 \mathrm{~mL} 3.75 \mathrm{mmol} / \mathrm{L}$ neocuproin. The absorbance was read at $450 \mathrm{~nm}$ after $30 \mathrm{~min}$. The results were expressed in terms of the water-soluble analog of vitamin E.

\section{Statistical Analysis}

The results were presented as mean \pm standard deviation (SD). The data were performed using one-way analysis of variance (ANOVA) followed by Tukey's test at $P<0.05$. All analyses were conducted using SPSS 20.0 for Windows.

\section{Results and Discussion}

\section{Effects of Different Oak Chips on Total Phenolics,} Total Flavonoids and Total Flavanols

Fig. 2-4 showed the effects of different species and amounts of oak slices to total phenolics, flavonoids and flavanols. Fig. 2 showed that samples aged in oak slices have higher total phenolic content compared with control sample $(0.038 \pm 0.002 \mathrm{mg} / \mathrm{mL})$. It has been reported that wines aged with oak chips during 45 days presented higher total phenolic content compared with the control wine, wines treated $3 \mathrm{~g} / \mathrm{L}$ of oak chips increased phenolic content and the wines containing with $5 \mathrm{~g} / \mathrm{L}$ had a lower phenolic content
(Dumitriu et al., 2016). However, in this study, the total phenolic contents increased along with oak chips content and the highest total phenol content $(0.083 \pm 0.001 \mathrm{mg} / \mathrm{mL})$ was observed when $6 \mathrm{~g} / \mathrm{L}$ of the French oak slices was used. The inconsistency between the results may be due to the difference of oak chip wood and baking degree. Fig. 3 showed that the addition of the oak slices can increase the total flavonoid content in the Longyan dry white wine. In the aging process of American and French oak slices, the $6 \mathrm{~g} / \mathrm{L}$ French oak slices had the highest total flavonoid contents $(0.063 \pm 0.001) \mathrm{mg} / \mathrm{mL}$. The results coincides with previous research, which pointed out that no difference in total flavonoid content was due to their participation in the oxidation reactions and American oak chips presented very low increment as the extraction proceeded. Fig. 4 showed that the aging effect of the oak slices on the total flavanol contents varied with the type and content of oak. Regardless of 2,4 , or $6 \mathrm{~g} / \mathrm{L}$ of American oak slices were added, no effect was observed on the total flavanol content. The total flavanol content in the control sample was only $0.004 \mathrm{mg} / \mathrm{mL}$ and the effect of oak slices treatment on total flavanol was not significant $(P<0.05)$.

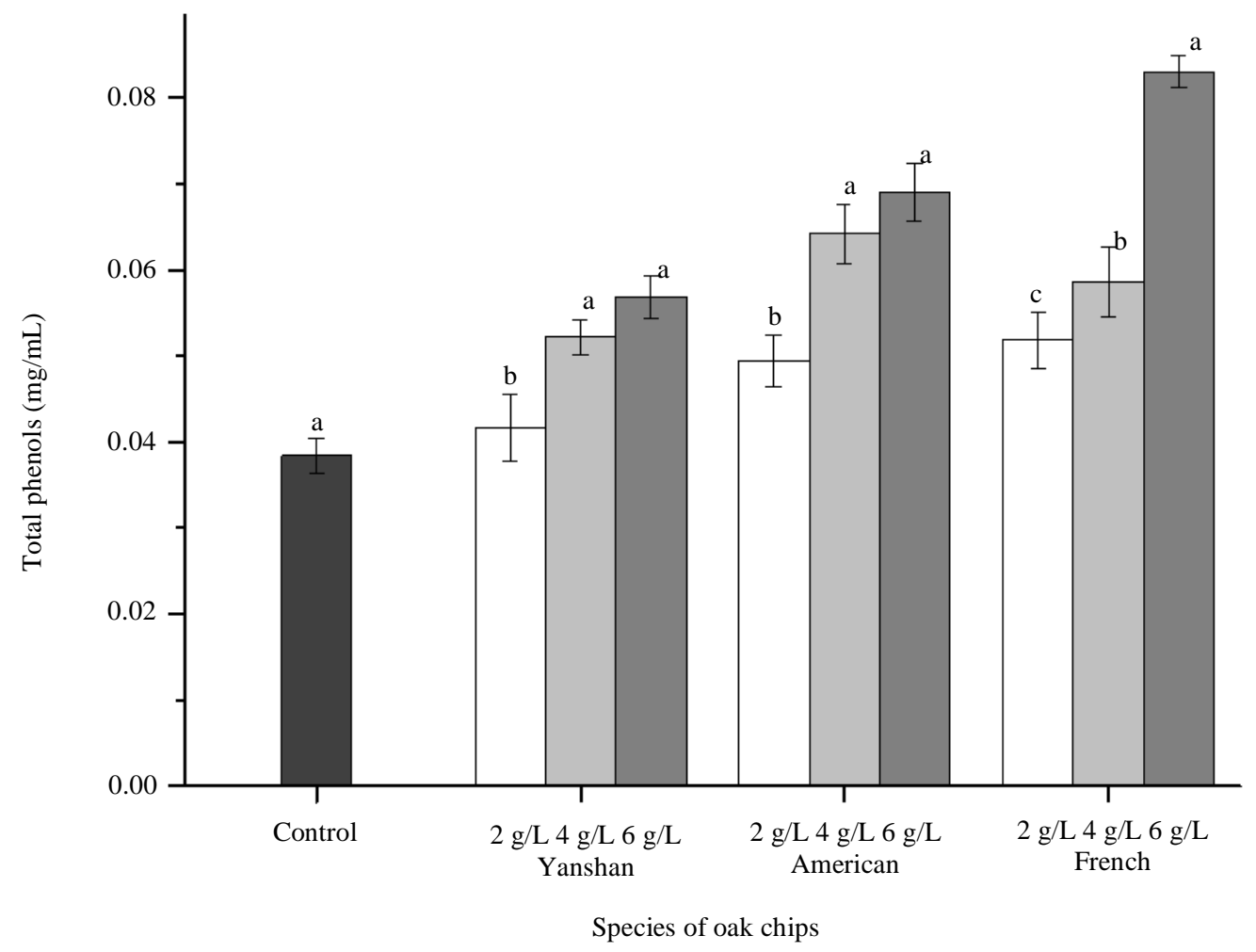

Fig. 2: Effect of different oak slices on total phenol content during aging of Longyan dry white wine. Different superscripts indicate statistical differences between different additions of the same oak chips $(P<0.05)$ 


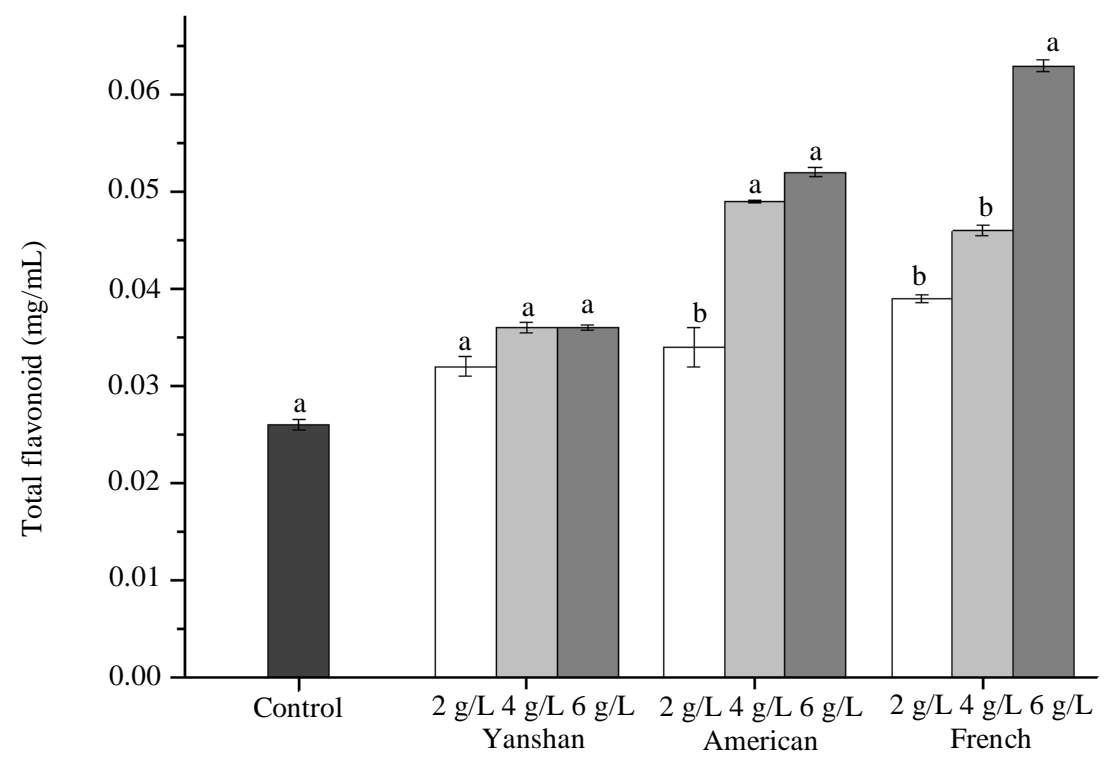

Species of oak chips

Fig. 3: Effect of different oak chips on total flavonoid content during aging of Longyan dry white wine. Different superscripts indicate statistical differences between different additions of the same oak chips $(P<0.05)$

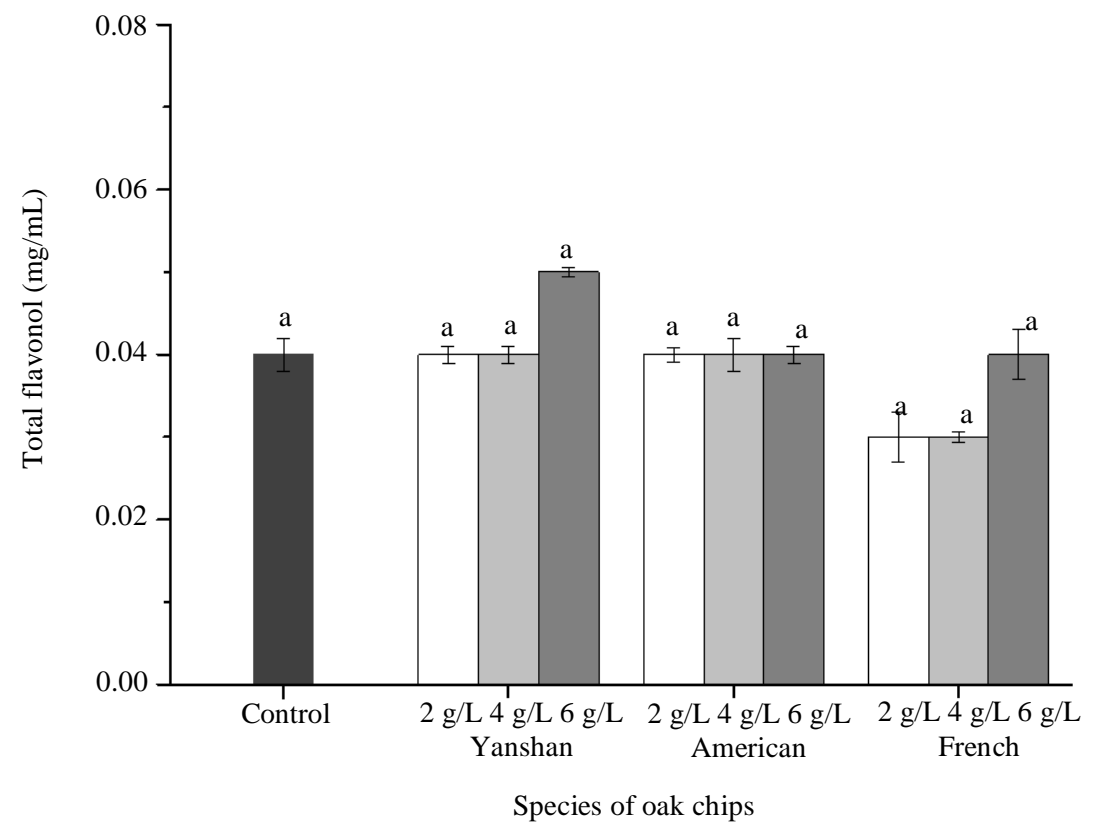

Fig. 4: Effect of different oak chips on total flavanol content during aging of Longyan dry white wine. Different superscripts indicate statistical differences between different additions of the same oak chips $(P<0.05)$

\section{Effects of Different Oak Chips on Monomeric} Phenol

The effects of different oak slices on 12 monomeric phenols were showed in Table 1 . In the Table 1, the content of most monomeric phenols was higher than that of the control wine sample. This finding showed that phenolic substances in aged oak were effectively immersed in wine samples. Among these phenols, the largest increase was guaiacol because oak is rich in guaiacol and guaiacol content increased with the added amount of oak slices. This result is inconsistent with that observed by previous research, the most abundant monomeric phenol in control wine samples were ellagic acid and gallic acid and the most abundant compounds were ellagic acid and sinapic aldehyde in wine samples aged with oak chips (Sanza et al., 2004). This may be due to different types of wood containing various low molecular phenolics, the release of 
the phenolic substances from wood to wine depends on the type of chips and the degree of toast during red wine aging. Derivatives of benzoic and cinnamic acid (such as benzoic acid, gallic acid, syringic acid, salicylic acid, coumaric acid and ferulic acid) are products of sugar degradation during wood roasting (Arapitsas et al., 2004; Natali et al., 2006). Therefore, after aging, the content of these derivatives increased and the wine sample aged with $6 \mathrm{~g} / \mathrm{L}$ French oak slices increased most, these results agree with those observed by other researches (Jordão et al., 2006; Jordão et al., 2012). This phenomenon was due to the high levels of lignin, cellulose, hemicellulose and other sugars degraded by medium-baked French oak (Baiano et al., 2015; Ortega-Heras et al., 2004). The syringicaldehyde is considered as markers in distilled beverages during aging and syringicaldehyde and vanillin comes from the degradation of lignin, it is used to evaluate the quality of aged samples (Doussot et al., 2002). Some authors reported that a ratio (syringicaldehyde/vanillin) from 1.4 to 2.5 indicates a balance in the lignin degradation (Michel et al., 2011). In this study, the syringaldehyde in the wine sample considerably changed after aging, French oak chips treated wine samples contain higher content of syringaldehyde, being higher than that reported (Michel et al., 2011). The syringaldehyde will turn into syringic acid after oxidation and the syringic acid in the wine sample did not substantially change, thus indicated that the wine sample had less contact with oxygen during aging, leading to low oxidation. Moreover, the overall change effect of various monomer phenols was similar to those of total phenol, flavonoids and flavanols.

\section{Effect of Different Oak Chips on Antioxidant Capacity}

Fig. 5 showed the effect of different oak slices on the total antioxidant capacity of Longyan dry white wine.
The wines aged with $6 \mathrm{~g} / \mathrm{L}$ French oak slices had the strongest total antioxidant capacity of $(47.853 \pm 0.360)$ $\mathrm{U} / \mathrm{mL}$, reaching thrice that of the control sample. The effects of Yanshan and American oak chips on the total antioxidant ability of wine samples were not extremely different. These results can be due to the influence of some parameters, as toasting intensity and origin of the oak wood piece studied. Fig. 6 showed the effect of different oak slices on DPPH free radical-scavenging rate. As shown in this figure, the aged wine with $6 \mathrm{~g} / \mathrm{L}$ American oak slices increased the DPPH free radicalscavenging rate from $(94.841 \% \pm 0.324)$ to $(97.545 \% \pm 0.331)$. However, some authors reported that light or medium toasting intensity of the oak chips presented higher antioxidant activity, the content of oak chips had little effect on the antioxidant capacity (António et al., 2012). DPPH free radicals are reduced by providing hydrogen atoms through antioxidant compounds, suggested that different species and contents of oak slices are considerably affected by the hydrogen supply capacity of antioxidant molecules in wine samples. Fig. 7 showed the hydroxyl radical-scavenging rate of different oak slices on Longyan dry white wine. As shown in this figure, the clearance rate $(74.731 \% \pm 0.430)$ of hydroxyl radicals was the highest in the aged sample with 2 $\mathrm{g} / \mathrm{L}$ Yanshan oak slices and the scavenging rate of hydroxyl radicals in the wine samples decreased as the amount of Yanshan oak slices increased. In the wine samples aged with American and French oaks, the scavenging rate of hydroxyl radicals increased as the amount of oak slices increased. And values for the clearance rate of hydroxyl radicals in French oak chips coincides with results reported by other authors in cognacs (Da Porto et al., 2000).

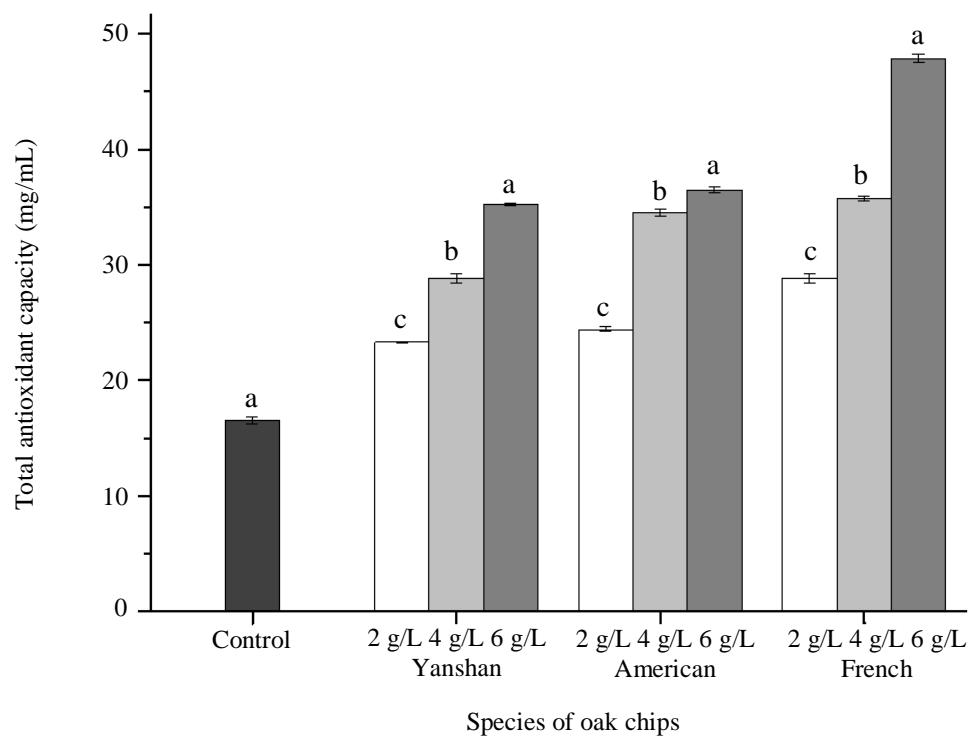

Fig. 5: Effect of different oak slices on total antioxidant capacity during aging of Longyan dry white wine. Different superscripts indicate statistical differences between different additions of the same oak chips $(P<0.05)$ 


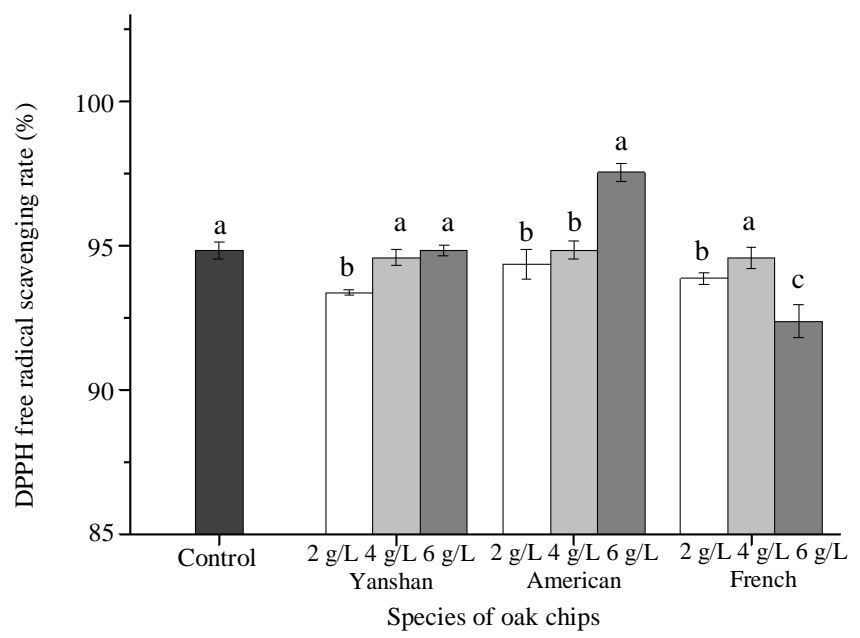

Fig. 6: Effect of different oak slices on DPPH radical scavenging rate during aging of Longyan dry white wine. Different superscripts indicate statistical differences between different additions of the same oak chips $(P<0.05)$

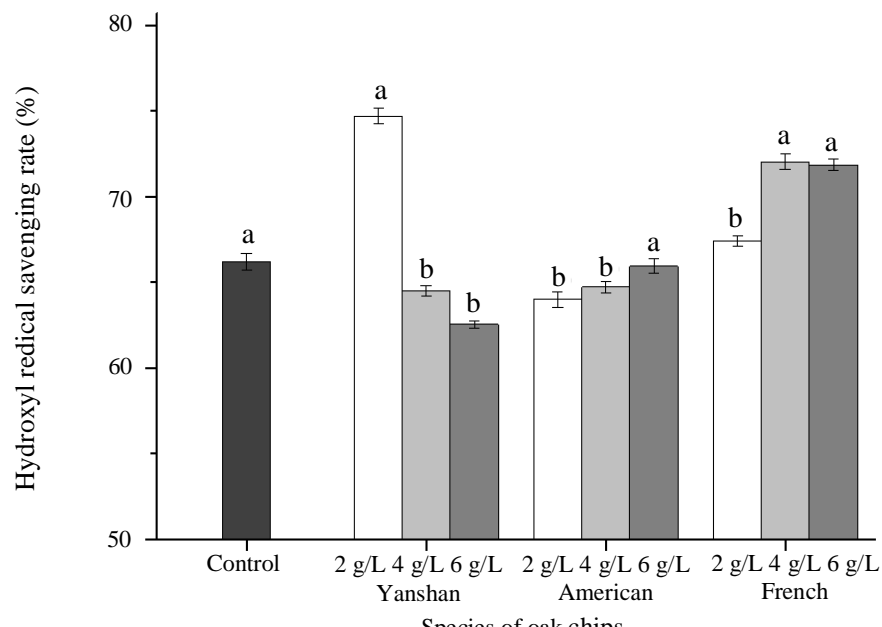

Fig. 7: Effect of different oak slices on hydroxyl radical scavenging rate during aging of Longyan dry white wine. Different superscripts indicate statistical differences between different additions of the same oak chips $(P<0.05)$

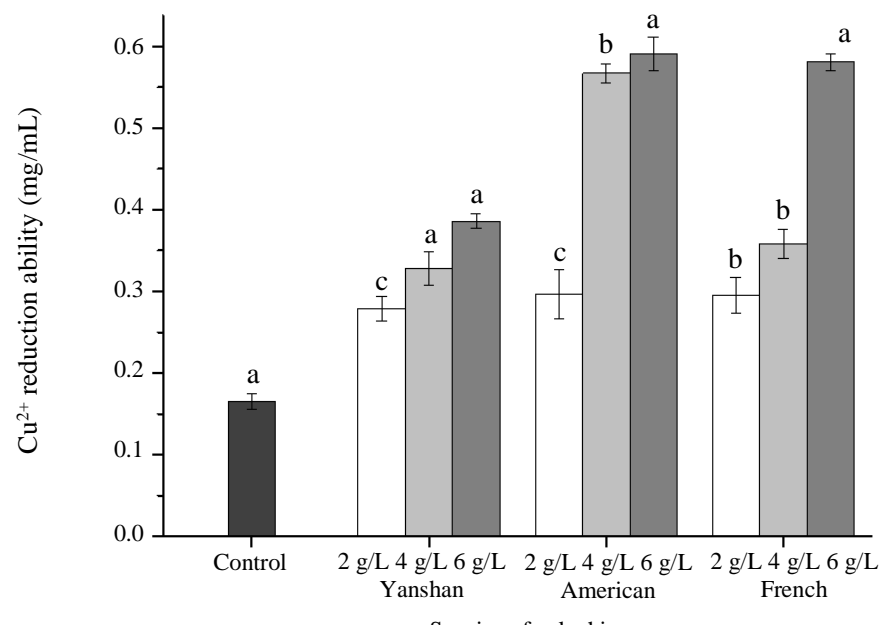

Species of oak chips

Fig. 8: Effect of different oak slices on $\mathrm{Cu}^{2+}$ reduction force during aging of Longyan dry white wine. Different superscripts indicate statistical differences between different additions of the same oak chips $(P<0.05)$ 
Table 1: Evolution of monomer phenols in Longyan dry white wines treated with different oak chips for 60 days

\begin{tabular}{|c|c|c|c|c|c|c|c|c|c|c|}
\hline \multirow{2}{*}{$\begin{array}{l}\text { Monomeric } \\
\text { phenol/(mg/L) }\end{array}$} & \multirow[b]{2}{*}{ Control } & \multicolumn{3}{|c|}{ Yanshan oak slices } & \multicolumn{3}{|c|}{ American oak slices } & \multicolumn{3}{|c|}{ French oak slices } \\
\hline & & $2 \mathrm{~g} / \mathrm{L}$ & $4 \mathrm{~g} / \mathrm{L}$ & $6 \mathrm{~g} / \mathrm{L}$ & $2 \mathrm{~g} / \mathrm{L}$ & $4 \mathrm{~g} / \mathrm{L}$ & $6 \mathrm{~g} / \mathrm{L}$ & $2 \mathrm{~g} / \mathrm{L}$ & $4 \mathrm{~g} / \mathrm{L}$ & $6 \mathrm{~g} / \mathrm{L}$ \\
\hline Gallic acid & $1.201 \pm 0.005^{\mathrm{a}}$ & $1.408 \pm 0.017^{\mathrm{c}}$ & $1.727 \pm 0.026^{\mathrm{b}}$ & $2.013 \pm 0.021^{\mathrm{a}}$ & $1.237 \pm 0.013^{\mathrm{c}}$ & $1.541 \pm 0.007^{\mathrm{b}}$ & $1.939 \pm 0.025^{\mathrm{a}}$ & $1.531 \pm 0.011^{\mathrm{b}}$ & $1.569 \pm 0.010^{\mathrm{b}}$ & $2.046 \pm 0.010^{\mathrm{a}}$ \\
\hline Protocatechuic acid & $3.271 \pm 0.023^{\mathrm{a}}$ & $3.418 \pm 0.026^{\mathrm{C}}$ & $4.039 \pm 0.015^{\mathrm{b}}$ & $6.125 \pm 0.037^{\mathrm{a}}$ & $3.323 \pm 0.006^{\mathrm{b}}$ & $4.042 \pm 0.041^{\mathrm{a}}$ & $4.532 \pm 0.011^{\mathrm{a}}$ & $3.451 \pm 0.024^{\mathrm{c}}$ & $4.327 \pm 0.001^{\mathrm{b}}$ & $5.436 \pm 0.023^{\mathrm{a}}$ \\
\hline Catechin & $1.323 \pm 0.033^{\mathrm{a}}$ & $1.033 \pm 0.007^{\mathrm{c}}$ & $1.476 \pm 0.009^{\mathrm{b}}$ & $2.012 \pm 0.011^{\mathrm{a}}$ & $1.379 \pm 0.014^{\mathrm{c}}$ & $1.432 \pm 0.037^{\mathrm{b}}$ & $1.784 \pm 0.019^{\mathrm{a}}$ & $0.916 \pm 0.001^{\mathrm{b}}$ & $0.947 \pm 0.005^{\mathrm{b}}$ & $1.472 \pm 0.016^{\mathrm{a}}$ \\
\hline Vanillic acid & $2.132 \pm 0.005^{\mathrm{a}}$ & $2.763 \pm 0.014^{\mathrm{c}}$ & $3.746 \pm 0.007$ & $5.372 \pm 0.029^{\mathrm{a}}$ & $3.023 \pm 0.021^{\mathrm{c}}$ & $5.135 \pm 0.015^{\mathrm{a}}$ & $5.983 \pm 0.033^{\mathrm{a}}$ & $3.014 \pm 0.032^{\mathrm{c}}$ & $4.735 \pm 0.025^{\mathrm{b}}$ & $6.028 \pm 0.019^{\mathrm{a}}$ \\
\hline Syringic acid & $1.753 \pm 0.012^{\mathrm{a}}$ & $1.923 \pm 0.043^{\mathrm{b}}$ & $2.132 \pm 0.005^{\mathrm{ab}}$ & $2.534 \pm 0.032^{\mathrm{a}}$ & $2.012 \pm 0.009^{c}$ & $2.541 \pm 0.012^{\mathrm{b}}$ & $3.017 \pm 0.012^{\mathrm{a}}$ & $2.031 \pm 0.009^{\mathrm{b}}$ & $3.012 \pm 0.003^{\mathrm{ab}}$ & $3.913 \pm 0.028^{\mathrm{a}}$ \\
\hline Coumalic acid & $2.412 \pm 0.027^{\mathrm{a}}$ & $2.441 \pm 0.003^{\mathrm{b}}$ & $2.407 \pm 0.026^{\mathrm{b}}$ & $3.012 \pm 0.004^{\mathrm{a}}$ & $2.531 \pm 0.018^{\mathrm{c}}$ & $3.267 \pm 0.023^{\mathrm{b}}$ & $4.007 \pm 0.036^{\mathrm{a}}$ & $2.331 \pm 0.017^{\mathrm{a}}$ & $2.512 \pm 0.001^{\mathrm{a}}$ & $2.673 \pm 0.020^{\mathrm{a}}$ \\
\hline Syringal dehyde & $1.032 \pm 0.023^{\mathrm{a}}$ & $3.211 \pm 0.065^{\mathrm{c}}$ & $9.435 \pm 0.522^{\mathrm{b}}$ & $11.581 \pm 1.301^{\mathrm{a}}$ & $3.033 \pm 0.065^{\mathrm{c}}$ & $10.807 \pm 0.065^{\mathrm{b}}$ & $12.925 \pm 0.065^{\mathrm{a}}$ & $3.411 \pm 0.023^{\mathrm{c}}$ & $12.213 \pm 0.023^{\mathrm{b}}$ & $15.134 \pm 0.023^{\mathrm{a}}$ \\
\hline Ferulic acid & $1.352 \pm 0.006^{\mathrm{a}}$ & $1.478 \pm 0.011^{\mathrm{a}}$ & $1.392 \pm 0.021^{\mathrm{a}}$ & $1.536 \pm 0.001^{\mathrm{a}}$ & $1.354 \pm 0.013^{\mathrm{b}}$ & $1.451 \pm 0.008^{\mathrm{a}}$ & $1.781 \pm 0.013^{\mathrm{a}}$ & $1.432 \pm 0.004^{\mathrm{a}}$ & $1.451 \pm 0.011^{\mathrm{a}}$ & $1.528 \pm 0.008^{\mathrm{a}}$ \\
\hline Benzoic acid & $3.712 \pm 0.022^{\mathrm{a}}$ & $3.943 \pm 0.015^{\mathrm{c}}$ & $4.375 \pm 0.001^{\mathrm{b}}$ & $6.019 \pm 0.047^{\mathrm{a}}$ & $4.121 \pm 0.037^{\mathrm{c}}$ & $5.672 \pm 0.006^{\mathrm{b}}$ & $8.315 \pm 0.001^{\mathrm{a}}$ & $5.349 \pm 0.022^{\mathrm{c}}$ & $8.716 \pm 0.014^{b}$ & $11.351 \pm 0.034^{\mathrm{a}}$ \\
\hline Salicylic acid & $5.207 \pm 0.001^{\mathrm{a}}$ & $5.834 \pm 0.029^{\mathrm{b}}$ & $6.719 \pm 0.034^{\mathrm{b}}$ & $9.341 \pm 0.009^{\mathrm{a}}$ & $6.145 \pm 0.026^{\mathrm{b}}$ & $7.181 \pm 0.022^{\mathrm{b}}$ & $11.707 \pm 0.021^{\mathrm{a}}$ & $7.803 \pm 0.013^{\mathrm{c}}$ & $8.143 \pm 0.037^{\mathrm{b}}$ & $13.217 \pm 0.101^{\mathrm{a}}$ \\
\hline Quercetin & $0.573 \pm 0.009^{\mathrm{a}}$ & $0.491 \pm 0.001^{\mathrm{b}}$ & $0.581 \pm 0.010^{\mathrm{b}}$ & $0.873 \pm 0.001^{\mathrm{a}}$ & $0.534 \pm 0.011^{\mathrm{a}}$ & $0.577 \pm 0.015^{\mathrm{a}}$ & $0.591 \pm 0.025^{\mathrm{a}}$ & $0.624 \pm 0.014^{\mathrm{b}}$ & $0.597 \pm 0.008^{\mathrm{b}}$ & $0.731 \pm 0.004^{\mathrm{a}}$ \\
\hline
\end{tabular}

Table 2: Correlation between phenols substances and antioxidation

\begin{tabular}{lllll}
\hline Phenols & $\begin{array}{l}\text { Total antioxidant } \\
\text { capacity }\end{array}$ & $\begin{array}{l}\text { DPPH free radical } \\
\text { scavenging rate }\end{array}$ & $\begin{array}{l}\text { Hydroxyl radical } \\
\text { scavenging rate }\end{array}$ & $\begin{array}{l}\mathrm{Cu}^{2+} \text { reduction } \\
\text { ability }\end{array}$ \\
\hline Gallic acid & 0.961 & 0.923 & 0.909 & 0.352 \\
Protocatechuic acid & 0.697 & 0.664 & 0.567 & -0.246 \\
Catechin & 0.770 & 0.761 & 0.641 & -0.079 \\
Vanillic acid & -0.434 & -0.549 & -0.595 & -0.335 \\
Syringic acid & 0.730 & 0.871 & 0.847 & 0.164 \\
Coumalic acid & 0.677 & 0.752 & 0.654 & -0.110 \\
Syringaldehyde & -0.806 & -0.892 & -0.839 & -0.181 \\
Ferulic acid & 0.922 & 0.970 & 0.937 & 0.247 \\
Guaiacol & -0.812 & -0.816 & -0.761 & 0.021 \\
Benzoic acid & -0.283 & -0.061 & -0.051 & -0.294 \\
Salicylic acid & 0.242 & 0.304 & 0.223 & -0.323 \\
Quercetin & 0.937 & 0.931 & 0.936 & 0.548 \\
\hline
\end{tabular}

Excessive metal ions in wine, such as $\mathrm{Cu}^{2+}$, are indirectly involved in oxidation through the catalysis of oxygen free radicals, resulted in the oxidation and deterioration of wine (Petit et al., 2013). $\mathrm{Cu}^{2+}$ reduction ability is the provision of electrons through antioxidants to restore $\mathrm{Cu}^{2+}$. Fig. 8 showed the effect of different oak chips on the $\mathrm{Cu}^{2+}$ reduction ability of wine samples. The $\mathrm{Cu}^{2+}$ reduction ability of increased with the increase of oak chips. A total of 4 and $6 \mathrm{~g} / \mathrm{L}$ American oak slices and $6 \mathrm{~g} / \mathrm{L}$ French oak slices had considerable influence on the $\mathrm{Cu}^{2+}$ reduction ability of the wine sample and the maximum value reached $0.591 \mathrm{mg} / \mathrm{mL}$. Compared with American and French oak, Yanshan oak had less influence on the $\mathrm{Cu}^{2+}$ reduction ability of the wine sample.

\section{Correlation Between Phenolic Substances and Antioxidation in Longyan Dry White Wine}

Numerous studies have showed that the oxidation resistance of phenolic substances is mainly reflected in two aspects. On the one hand, the oxygen content in the environment is reduced by redox reaction (Oberholster et al., 2015; Aruwa et al., 2019). In this process, phenolic substances simultaneously act as hydrogen donors to release hydrogen into the environment. The combination of free radicals terminates the chain reaction initiated by free radicals, thereby preventing the commencement of the oxidation process. On the other hand, polyphenols can effectively remove excessive free radicals in the body, inhibit oxidation and protect against free radical-induced damage to biological macromolecules (Navarro et al., 2016; Pérez-Coello et al., 2000).

In order to evaluate the contribution of phenolic substances measured to the antioxidant capacity, correlation analysis was used. Table 2 showed that a certain correlation existed between phenolic content and antioxidation. This result showed that a strong positive correlation was observed between gallic acid, ferulic acid, quercetin and total antioxidant capacity, as well as in DPPH free radical-scavenging rate and hydroxyl radicalscavenging rate, is inconsistent with other results. According to other authors, positive correlations were observed between the concentration of total ellagitannis quantified and the total antioxidant activity (António et al., 2012). Additionally, syringaldehyde was negatively correlated with total antioxidant capacity, DPPH radical scavenging rate and hydroxyl radical scavenging rate. The correlation between various phenolic substances and $\mathrm{Cu}^{2+}$ reduction ability was weak. These findings may be related to the participation of $\mathrm{Cu}^{2+}$ in the oxidation reaction through the catalytic action of oxygen radicals.

\section{Conclusion}

The phenolic substances and antioxidant activities of Longyan dry-white wine aged by three different oak slices were determined. The results showed that samples aged in oak slices have higher total phenolic content 
compared with control sample and the content of total phenol and flavonoids was the highest in $6 \mathrm{~g} / \mathrm{L}$ French oak slices. After aging in oak slices, the content of monomeric phenols increased and guaiacol showed the largest increase, whereas the $6 \mathrm{~g} / \mathrm{L}$ French oak slices had the largest influence on monomeric phenols. Different oak slices showed different effects on antioxidant activity: $6 \mathrm{~g} / \mathrm{L}$ French oak slices presented higher total antioxidant capacity; $6 \mathrm{~g} / \mathrm{L}$ American oak slices presented higher DPPH free radical-scavenging rate; 2 $\mathrm{g} / \mathrm{L}$ Yanshan oak slices presented higher hydroxyl radical-scavenging rate; and 4 or $6 \mathrm{~g} / \mathrm{L}$ American oak slices and $6 \mathrm{~g} / \mathrm{L}$ of French oak slices presented strong $\mathrm{Cu}^{2+}$ reduction ability. A certain correlation was observed between phenolic content and antioxidation, gallic acid, ferulic acid and quercetin have a strong correlation with the total antioxidant capacity, DPPH free radical scavenging rate and hydroxyl radical scavenging rate and the correlation coefficient is more than 0.9. These results showed that the three substances in the monomer phenol contributed the most to the antioxidant capacity of wine. All in all, our research improves the knowledge about the potential effect of the use of oak chip and oak chip species on dry-white wine quality, the wine treated with $6 \mathrm{~g} / \mathrm{L}$ French oak slices has better quality in this study. So it lays the foundation for the extensive use of oak chips in aged wine in wine industry. The main monomers phenols which play an antioxidant role in wine aging were discovered and the next step of the antioxidant mechanism of wine can start with them.

\section{Funding Information}

This work was supported by the key research and development program of Hebei Province in China (No. 19227120D) and the Innovation capability promotion program of Hebei Province in China (No. 199676183H).

\section{Author's Contributions}

Rongbin Li: Has contributed in all experiments, paper writing and publication.

Xiaofang Liang: Has contributed in the paper writing, assisted in the experiment.

Chunhua Song and Haoran Wang: Have assisted in the experiment.

Yaqiong Liu, Yanli Ma and Jianfeng Sun: Have reviewed and revised the manuscript.

Jie Wang: has organized the study, reviewed and revised the manuscript.

\section{Ethics}

There are not any ethical issues to declare that could arise after the publication of this manuscript.

\section{Conflict of Interest}

The authors declare that they have no competing interests.

\section{References}

Alamo-Sanza, M. del, I. Nevares, A. Martínez-Gil, P. Rubio-Bretón and T. Garde-Cerdán, 2019. Impact of long bottle aging (10 years) on volatile composition of red wines micro-oxygenated with oak alternatives. LWT-Food Sci. Technol., 101: 395-403. DOI: 10.1016/j.lwt.2018.11.049

Apak, R., K. Güçlü, M. Özyürek and S.E. Karademir, 2004. Novel total antioxidant capacity index for dietary polyphenols and vitamins $\mathrm{C}$ and $\mathrm{E}$, using their cupric ion reducing capability in the presence of neocuproine: CUPRAC method. J. Agr. Food Chem., 52: 7970-7981. DOI: 10.1021/jf048741x

Arapitsas, P., A. Antonopoulos, E. Stefanou and V.G. Dourtoglou, 2004. Artificial aging of wines using oak chips. Food Chem., 86: 563-570.

DOI: 10.1016/j.foodchem.2003.10.003

Arasaretnam, S. and T. Kirudchayini, 2019. Studies on synthesis, characterization of modified phenol formaldehyde resin and metal adsorption of modified resin derived from lignin biomass. Emerg. Sci. J., 3: 101-108.

DOI: $10.28991 /$ esj-2019-01173

Aruwa, C.E., S. Amoo and T. Kudanga, 2019. Phenolic compound profile and biological activities of Southern African Opuntia ficus-indica fruit pulp and peels. LWT-Food Sci. Technol., 111: 337-344.

DOI: $10.1016 /$ j.lwt.2019.05.028

Baiano, A., A. De Gianni, A. Mentana, M. Quinto and D. Centonze et al., 2015. Effects of the treatment with oak chips on color-related phenolics, volatile composition and sensory profile of red wines: the case of Aglianico and Montepulciano. Eur. Food Res. Technol., 242: 745-767. DOI: $10.1007 / \mathrm{s} 00217-015-2583-y$

Bautista-Ortín, A.B., A.G. Lencina, M. Cano-López, F. Pardo-Mínguez and J.M. López-Roca et al., 2008. The use of oak chips during the ageing of a red wine in stainless steel tanks or used barrels: Effect of the contact time and size of the oak chips on aroma compounds. Aust. J. Grape Wine R., 14: 63-70. DOI: $10.1111 /$ j.1755-0238.2008.00008.x

Bozalongo, R., J.D. Carrillo, M.Á.F. Torroba and M.T. Tena, 2007. Analysis of French and American oak chips with different toasting degrees by headspace solid-phase microextraction-gas chromatographymass spectrometry. J. Chromatogram A., 1173: 10-17. DOI: 10.1016/j.chroma.2007.09.079 
Canas, S., I. Caldeira, O. Anjos and A.P. Belchior, 2019. Phenolic profile and colour acquired by the wine spirit in the beginning of ageing: Alternative technology using micro-oxygenation vs traditional technology. LWT-Food Sci. Technol., 111: 260-269. DOI: 10.1016/j.lwt.2019.05.018

Cerdán, T.G. and C. Ancín-Azpilicueta, 2006. Effect of oak barrel type on the volatile composition of wine: Storage time optimization. LWT-Food Sci. Technol., 39: 199-205. DOI: 10.1016/j.lwt.2005.01.009

Cerdán. T.G., S.R. Mozaz and C.A Azpilicueta, 2002. Volatile composition of aged wine in used barrels of French oak and of American oak. Food Res. Int., 35: 603-610. DOI: 10.1016/s0963-9969(01)00151-x

Coelho, E., J.A. Teixeira, L. Domingues, T. Tavares and J.M. Oliveira, 2019. Factors affecting extraction of adsorbed wine volatile compounds and wood extractives from used oak wood. Food Chem., 295: 156-164. DOI: 10.1016/j.foodchem.2019.05.093

Crump, A.M., T.E. Johnson, K.L. Wilkinson and S.E.P. Bastian, 2015. Influence of oak maturation regimen on composition, sensory properties, quality and consumer acceptability of cabernet sauvignon wines. J. Agr. Food Chem., 63: 1593-1600.

DOI: $10.1021 /$ jf5044025

Da Porto, C., S. Calligaris, E. Celloti and M.C. Nicoli, 2000. Antirradical properties of commercial Cognacs assessed by the DPPH• test. J. Agr. Food Chem., 48: 4241-4245. DOI: 10.1021/jf000167b

Doussot, F., B. De Jéso, S. Quideau and P. Pardon, 2002. Extractives content in cooperage oak wood during natural seasoning and toasting; Influence of tree species, geographic location and single tree effects. J. Agric. Food Chem., 50: 5955-5961.

DOI: $10.1021 /$ jf020494e

Dumitriu, Georgiana-Diana, N.L. de Lerma, V.V. Cotea, Cătălin-Ioan Zamfir and R.A. Peinado, 2016. Effect of aging time, dosage and toasting level of oak chips on the color parameters, phenolic compounds and antioxidant activity of red wines (var. Feteasc $\ddot{A} f$ neagr $\ddot{f}$ ). Eur. Food Res. Technol., 242: 2171-2180. DOI: $10.1007 / \mathrm{s} 00217-016-2714-0$

Gómez García-Carpintero, E., M.A. Gómez Gallego, E. Sánchez-Palomo and M.A. González Viñas, 2012. Impact of alternative technique to ageing using oak chips in alcoholic or in malolactic fermentation on volatile and sensory composition of red wines. Food Chem., 134: 851-863.

DOI: 10.1016/j.foodchem.2012.02.194

Gordillo, B., B. Baca-Bocanegra, F.J. Rodriguez-Pulído, M.L. González-Miret and I. García Estévez et al., 2016. Optimisation of an oak chips-grape mix maceration process. Influence of chip dose and maceration time. Food Chem., 206: 249-259.

DOI: 10.1016/j.foodchem.2016.03.041
Guchu, E., M.C. Díaz-Maroto, M.S. Pérez-Coello, M.A. González-Viñas and M.D. Cabezudo Ibáñez, 2005. Volatile composition and sensory characteristics of Chardonnay wines treated with American and Hungarian oak chips. Food Chem., 99: 350-359. DOI: $10.1016 /$ j.foodchem.2005.07.050

Jordão, A.M., J.M. Ricardo-da-Silva and O. Laureano, 2006. Role of oak wood extract, ellagic acid and oxygen on malvidin-3-glucoside, catechin and colour parameters evolution in model wine solutions. Am. J. Enol. Vitic., 57: 377-381. DOI: $10.1111 /$ j.1755-0238.2008.00029.x

Jordão, A.M., A.C. Correia, R. DelCampo and M.L.G. SanJosé, 2012. Antioxidant capacity, scavenger activity and ellagitannins content from commercial oak pieces used in winemaking. Eur. Food Res. Technol., 235: 817-825.

DOI: $10.1007 / \mathrm{s} 00217-012-1803-y$

Kyraleou, M., S. Kallithraka, K. Chira, E. Tzanakouli and I. Ligas et al., 2015. Differentiation of wines treated with wood chips based on their phenolic content, volatile composition and sensory parameters. J. Food Sci., 80: C2701-C2710. DOI: $10.1111 / 1750-3841.13125$

Mahboubi, M. and M. Mahboubi, 2015. Chemical composition, antimicrobial and antioxidant activities of Eugenia caryophyllata essential oil. J. Essent. Oil Bear Pl., 18: 967-975.

DOI: $10.1080 / 0972060 X .2014 .884779$

Michel, J., M. Jourdes, M.A. Silva, T. Giordanengo and N. Mourey et al., 2011. Impact of concentration of ellagitannins in oak wood on their levels and organoleptic influence in red wine. J. Agric. Food Chem., 59: 5677-5683. DOI: 10.1021/jf200275w

Natali, N., F. Chinnici and C. Riponi, 2006. Characterization of volatiles in extracts from oak chips obtained by Accelerated Solvent Extraction (ASE). J. Agr. Food Chem., 54: 8190-8198. DOI: $10.1021 /$ jf0614387

Navarro, M., N. Kontoudakis, T. Giordanengo, S. Gómez-Alonso and E. García-Romero et al., 2016. Oxygen consumption by oak chips in a model wine solution; Influence of the botanical origin, toast level and ellagitannin content. Food Chem., 199: 822-827. DOI: 10.1016/j.foodchem.2015.12.081

Oberholster, A., B.L. Elmendorf, L.A. Lerno, E.S. King and H. Heymann et al., 2015. Barrel maturation, oak alternatives and micro-oxygenation: Influence on red wine aging and quality. Food Chem., 173: 1250-1258. DOI: 10.1016/j.foodchem.2014.10.043

Ortega-Heras, M., C. González-Huerta, P. Herrera and M.L. González-Sanjosé, 2004. Changes in wine volatile compounds of varietal wines during ageing in wood barrels. Anal. Chim. Acta., 513: 341-350. DOI: $10.1016 /$ j.aca.2003.10.051 
Pérez-Coello, M.S., M.A. González-Viñas, E. GarcíaRomero, M.D. Cabezudo and J. Sanz, 2000. Chemical and sensory changes in white wines fermented in the presence of oak chips. Int. J. Food Sci. Tech., 35: 23-32.

DOI: 10.1046/j.1365-2621.2000.00337.x

Petit, E., D. Lefeuvre, R. Jacquet, L. Pouységu and D. Deffieux et al., 2013. Remarkable biomimetic chemoselective aerobic oxidation of flavanoellagitannins found in Oak-Aged Wine. Angew. Chem., 125: 11744-11747.

DOI: 10.1002/ange.201305839

Prahadeesh, N., M. Sithambaresan and U. Mathiventhan, 2018. A study on hydrogen peroxide scavenging activity and ferric reducing ability of simple coumarins. Emerg. Sci. J., 2: 417-427.

DOI: 10.28991/esj-2018-01161
Sánchez-Palomo, E., R. Alonso-Villegas, J.A. Delgado and M.A. González-Viñas, 2017. Improvement of Verdejo white wines by contact with oak chips at different winemaking stages. LWT-Food Sci. Technol., 79: 111-118.

DOI: 10.1016/j.lwt.2016.12.045

Sedghamiz, A., M. Heidarpour, M. Reza Nikoo and S. Eslamian, 2018. A Game Theory approach for conjunctive use optimization model based on virtual water concept. Emerg. Sci. J., 4: 1315-1325.

DOI: $10.28991 /$ cej-0309175 